\title{
Transcutaneous oxygen and carbon dioxide monitoring in intensive care
}

\author{
D MARSDEN, M C CHIU, F PAKY, AND P HELMS \\ Hospital for Sick Children, Institute of Child Health, London
}

SUmmary Transcutaneous oxygen $\left(\mathrm{TcPo}_{2}\right)$ and carbon dioxide $\left(\mathrm{TcPcO}_{2}\right)$ tensions were compared with arterial values in 23 children aged 4 months to 14 years, all requiring some form of respiratory support, but not in shock. Electrodes were placed on the upper chest and were heated to $45^{\circ} \mathrm{C}$. For $\mathrm{TcPo}_{2}$ and arterial oxygen $\left(\mathrm{PaO}_{2}\right)$ a tight linear correlation over the range 6 to $14 \mathrm{kPa}$ ? was found. Arterial carbon dioxide $\left(\mathrm{PaCO}_{2}\right)$ ranged between 2.63 and $6.8 \mathrm{kPa}$, and over this range a linear regression adequately described the relation of $\mathrm{TcPCO}_{2}$ to $\mathrm{PaCO}_{2}$.

No effects of age were found for the relation between $\mathrm{TcPo}_{2}$ and $\mathrm{PaO}_{2}$. Over a four hour $\mathrm{O}$ period, the mean ratio $\mathrm{TcPo}_{2} / \mathrm{PaO}_{2}$ rose significantly from 0.96 to 1.04 , while the mean ratio of $\overrightarrow{ }$ $\mathrm{TcPCO}_{2} / \mathrm{PaCO}_{2}$ fell from 1.65 to $1 \cdot 62$. Five children developed superficial burns which were still $\mathbb{D}$ present at 48 hours. In children who require respiratory support but are not in shock, $\mathrm{TcPo}_{2}$ and

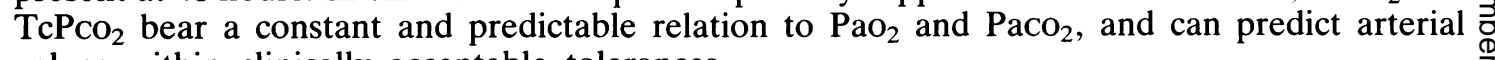
values within clinically acceptable tolerances.

Transcutaneous oxygen $\left(\mathrm{TcPo}_{2}\right)$ measurements have been widely used in neonatal units for many years, ${ }^{1}$ and are beginning to gain wider acceptance in adult intensive care. ${ }^{2-7}$ Transcutaneous carbon dioxide $\left(\mathrm{TcPCO}_{2}\right)$ measurements are less well established. ${ }^{136}$ In previous studies, highly significant linear correlations have been found for $\mathrm{TcPo}_{2}$ and $\mathrm{PaO}_{2}$ with $\mathrm{TcPCO}_{2}$ generally lower than simultaneous arterial values, particularly at high arterial tensions. The $\mathrm{TcPCO}_{2}$ value is higher than simultaneous arterial values because the skin produces $\mathrm{CO}_{2},{ }^{89}$ and local heat has an effect via the anaerobic heating coefficient of blood. ${ }^{10}$ The information that is available on the use of these transcutaneous techniques in children is limited by the non-independent nature of the data, as most studies include multiple measurements from the same subjects and transcutaneous/arterial comparisons were made at different times, ranging from 30 minutes to three hours after electrode placement..$^{2-5}$ We therefore undertook a study to evaluate the reliability and accuracy of transcutaneous gas measurements in children requiring respiratory support, and to observe any effects of time and the child's age.

\section{Patients and methods}

We measured $\mathrm{TcPo} 2 / \mathrm{CO}_{2}$ and $\mathrm{PaO}_{2} / \mathrm{CO}_{2}$ in 23 children aged from 4 months to 14 years, all of whom we receiving some form of respiratory support (mechanical ventilation, continuous distending pressure or $\overline{0}$ supplemental oxygen, or both). We used Roche $\frac{\circ}{\varnothing}$ Kontron 632 and 634 oxygen and carbon dioxide $\varrho$ electrodes heated to $45^{\circ} \mathrm{C}$. Oxygen electrodes were $\overrightarrow{\overrightarrow{0}}$ calibrated in room air according to barometric 3 pressure and allowed to stabilise. Carbon dioxide electrodes were calibrated at room temperature with humidified 5 and $10 \% \mathrm{CO}_{2}$. Between studies, $\mathrm{CO}_{2}$ electrodes were kept over bicarbonate storage solutions to maintain membrane saturation with $\frac{5}{3}$ $\mathrm{CO}_{2}$. Membranes were changed at weekly intervals unless stable air calibration for $\mathrm{O}_{2}$ electrodes could $\mathrm{O}$ not be obtained within 30 minutes and two point $\mathrm{CO}_{2}$ electrode calibration within one hour. After 윽 calibration, electrodes were placed on the upper $\supset$ chest and sampling began after in vivo stabilisation. Duplicate arterial samples were then taken at hourly $\tilde{O}$ intervals avoiding periods of physiotherapy, nursing or medical procedures, and endotracheal suction. $\tilde{N}$ Both $\mathrm{TcPo}_{2}$ and $\mathrm{TcPcO}_{2}$ were continuously recorded, and time base records inspected after arterial $\sigma$ sampling to ensure that comparisons were made 0

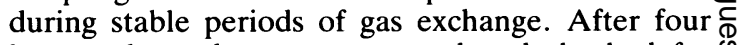
hours, electrodes were removed and checked for $\stackrel{\oplus}{+}$ drift with air or 5 and $10 \% \mathrm{CO}_{2}$ as appropriate. The 0 sites of electrode placement were inspected $\stackrel{\vec{\Phi}}{\circ}$ 
immediately and at 24 and 48 hours. Blood samples were drawn from indwelling arterial lines (radial or femoral) and measured on an IL 613 machine within three minutes. This machine was calibrated with standard reference solutions twice daily and checked with tonometered blood at weekly intervals. Results are expressed as means and ranges or standard deviations, or both. Differences between ratios of transcutaneous and arterial gas tensions were tested for significance with paired Student's $t$ tests.

\section{Results}

Mean time for $\mathrm{O}_{2}$ electrode in vitro stabilisation was 5 minutes (range 3 to 14 ). For $\mathrm{CO}_{2}$ electrodes, the mean time for two point calibration was 41 minutes (range 28 to 58). Times for in vivo stabilisation were 14.4 minutes (10 to 30) for $\mathrm{TcPo}_{2}$ and 10.5 ( 3 to 30) for $\mathrm{TcPCO}_{2}$. Electrode drifts over the four hour period were $\pm 0.4 \mathrm{kPa}(3 \mathrm{mmHg})$ range 0 to $1.2 \mathrm{kPa}$ (0 to $9 \mathrm{mmHg}$ ) for $\mathrm{TcPo}_{2}$ and $\pm 0.4 \mathrm{kPa}(3 \mathrm{mmHg})$ range 0 to $1.33 \mathrm{kPa}\left(0\right.$ to $10 \mathrm{mmHg}$ ) for $\mathrm{TcPCO}_{2}$. For $\mathrm{TcPO}_{2}$ and $\mathrm{PaO}_{2}$ a close agreement was found for samples up to arterial tensions of $14 \mathrm{kPa}$ (105 $\mathrm{mmHg}$ ). Above this arterial value, transcutaneous tensions significantly underestimated $\mathrm{PaO}_{2}$ (Fig. 1). For $\mathrm{TcPCO}_{2}$ and $\mathrm{PaCO}_{2}$ a linear correlation adequately described all data over the range of $\mathrm{PaCO}_{2}$ 2.63 to $6.8 \mathrm{kPa}(19.7$ to $51 \mathrm{mmHg}$ ) (Fig. 1). No effects of age were found for the ratio $\mathrm{TcPo}_{2} / \mathrm{PaO}_{2}$ over the range of data 6 to $14 \mathrm{kPa}(40$ to $105 \mathrm{mmHg}$ ) (Fig. 2). Transcutaneous oxygen tension/ $\mathrm{PaO}_{2}$ changed with time and rose between hours two and three, after which the ratio stabilised (Fig. 3). A similar but inverse relation for $\mathrm{TcPCO} / \mathrm{PaCO}_{2}$ was also found over this same period (Fig. 5). This amounted to an increase of approximately $0.67 \mathrm{kPa}$ $(5 \mathrm{mmHg})$ for $\mathrm{TcPo}_{2}$ and a decrease of $0.4 \mathrm{kPa} \mathrm{(3}$ $\mathrm{mmHg}$ ) for $\mathrm{TcPCO}_{2}$. Superficial burns were noted in five of 23 children at 24 and 48 hours.

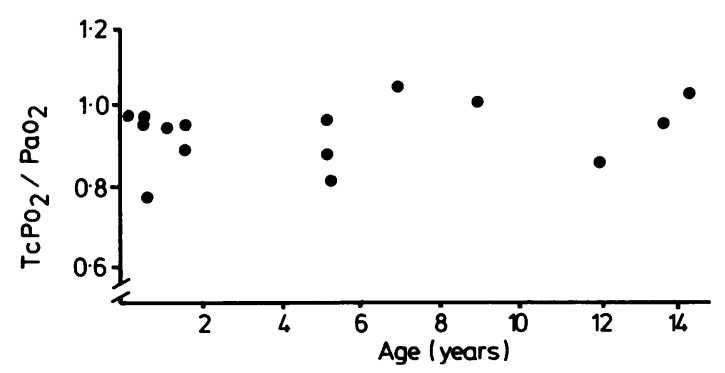

Fig. $2 \mathrm{TcPO}_{2} / \mathrm{PaO}_{2}$ for the 15 children with arterial values of $14 \mathrm{kPa}(105 \mathrm{mmHg})$ or less related to age.

No significant effects for age were found $r=0 \cdot 15(P>0 \cdot 5)$. All data taken at 1 hour after electrode placement.
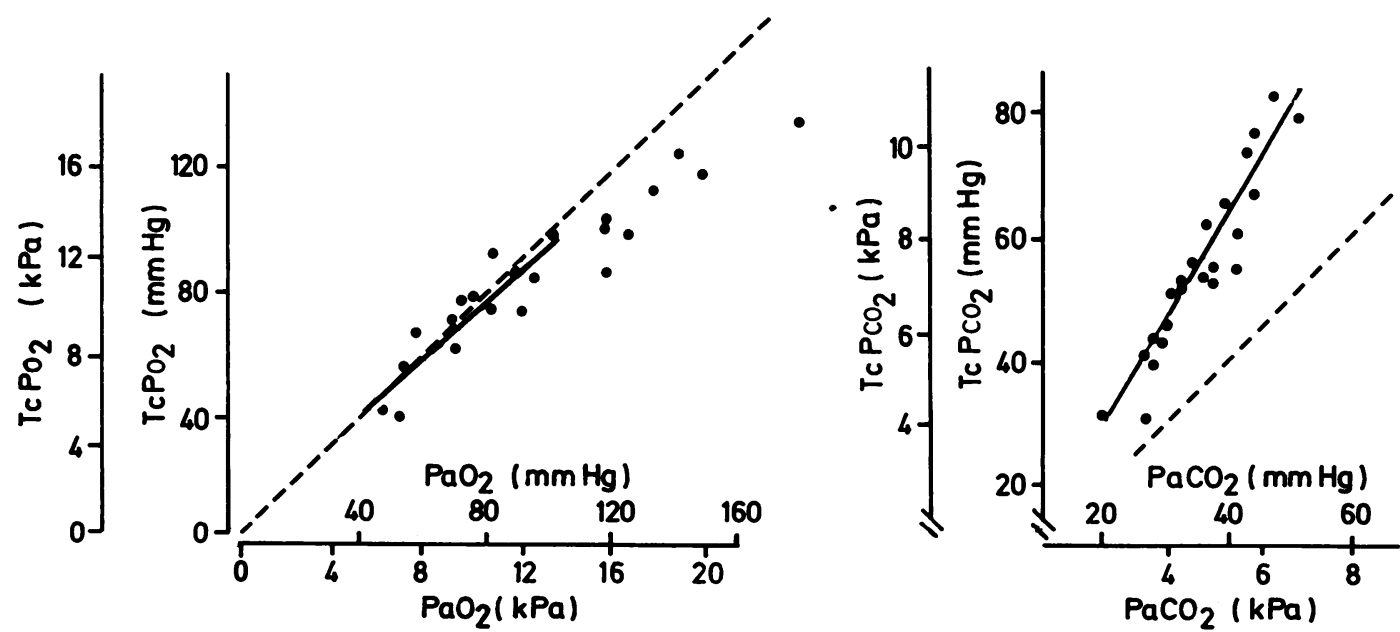

Fig. 1 Scattergram showing relation between transcutaneous and arterial gases at one hour after electrode placement in 23 children age 4 months to 14 years.

All children required respiratory support but none were in clinical shock. All measurements at electrode temperature of 45 degrees $C$. $\mathrm{TcPO}_{2}=\mathrm{PaO}_{2} \times 0.95+0.04 \mathrm{kPa}(0.31 \mathrm{mmHg}) \mathrm{r}=0.94$ (over range $6-14 \mathrm{kPa}$ ).

$\mathrm{TcPCO}_{2}=\mathrm{PaCO}_{2} \times 1.69-0.59 \mathrm{kPa}(4.46 \mathrm{mmHg}) \mathrm{r}=0.91$ (over whole range)

Note the curvelinear relation of the oxygen data and deviation from the line of identity above $14 \mathrm{kPa}(105 \mathrm{mmHg})$ arterial. 


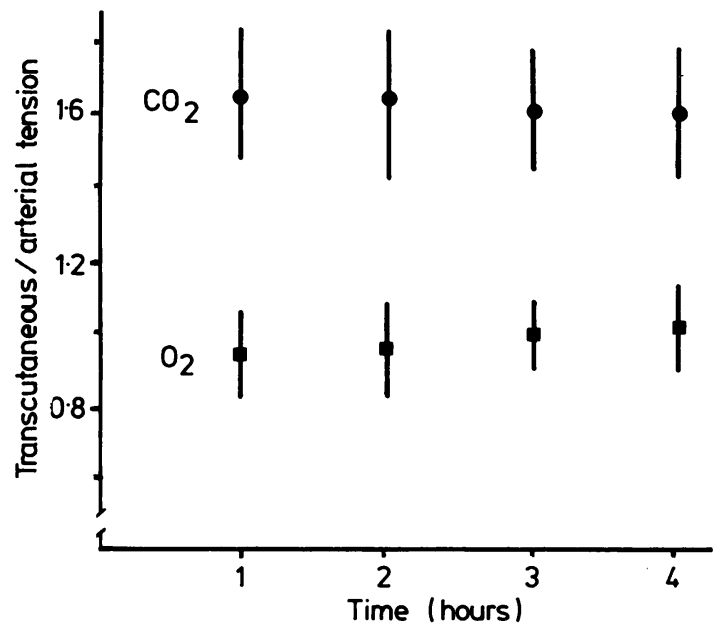

Fig. 3 Mean and standard deviations of $\mathrm{TcPO}_{2} / \mathrm{PaO}_{2}$ and $\mathrm{TCPCO}_{2} / \mathrm{PaCO}_{2}$ over 4 hours.

Data were restricted to the values of $\mathrm{PaO}_{2} 14 \mathrm{kPa}(105 \mathrm{mmHg})$ or less $(\mathrm{n}=15)$ in order to avoid spurious changes in the ratio $\mathrm{TcPO}_{2} / \mathrm{PaO}_{2},{ }^{11}$ and for the same reason $\mathrm{TcPCO}_{2} / \mathrm{PaCO}_{2}$ data were confined to sequential values of $\mathrm{PaCO}_{2}$ which changed by less than $0.66 \mathrm{kPa}(5 \mathrm{mmHg})(n=18)$. Results for hours 1 and 2 were significantly different on paired $t$ testing to those at hours 3 and 4 $(\mathrm{P}<0 \cdot 05)$.

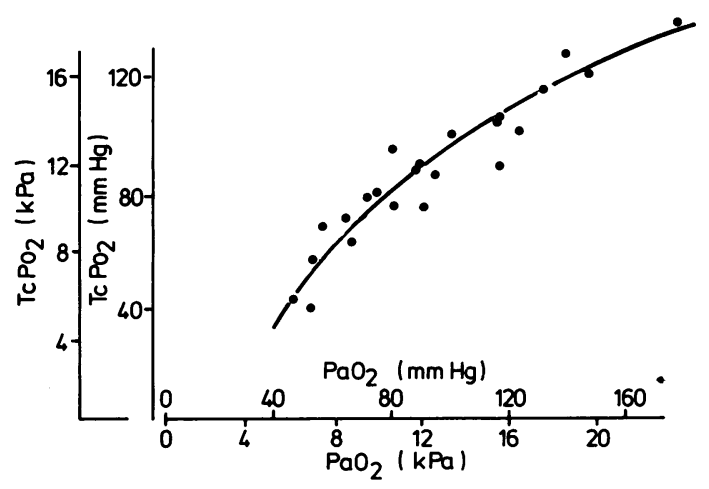

Fig. 4 The same $\mathrm{TcPO}_{2} / \mathrm{PaO}_{2}$ data as in Fig. 1 fitted with a logarithmic curve ( $\mathrm{TcPO}_{2}$ transformed to log 10).

\section{Discussion}

We chose $45^{\circ} \mathrm{C}$ for our study because we felt this would give the greatest degree of skin arterialisation and provide useful reference data for comparisons at lower electrode temperatures. The high proportion of children with burns (approximately $20 \%$ ) suggests that $45^{\circ} \mathrm{C}$ would be unsuitable for routine monitoring.
The close relation between transcutaneous and arterial oxygen, up to $14 \mathrm{kPa}(105 \mathrm{mmHg})$ arterial, $\stackrel{\vec{\Rightarrow}}{\vec{F}}$ with an increasing underestimation of $\mathrm{PaO}_{2}$ by $\mathrm{TcPo}_{2} \stackrel{9}{?}$ above that value is in agreement with previous studies. $^{2-5}$ As these data diverged from the line of $\frac{\bar{\sigma}}{\vec{F}}$ identity, we fitted a logarithmic curve to our results, $\frac{\text { ? }}{\triangle}$ an approach that described all data with reasonable $\underset{\complement}{\mathscr{Q}}$ accuracy (Fig. 4). This suggests a role for linearising circuits to estimate $\mathrm{PaO}_{2}$ from $\mathrm{TcPo}_{2}$ at higher $\vec{\circ}$ arterial tensions. The tight linear correlation between $\mathrm{TcPCO}_{2}$ and $\mathrm{PaCO}_{2}$ over the range 2.63 to $6.8 \mathrm{kPa} \vec{\omega}$ $(19.7$ to $51 \mathrm{mmHg})$ arterial, confirms previous $\stackrel{\circ}{\circ}$ studies $^{36}$ and emphasises the importance of 2 point $\stackrel{0}{\circ}$ calibration for this technique as the regression line? does not pass through the origin. Use of a ratio ? standard to 'correct' $\mathrm{TcPcO}_{2}$ would overestimate $\vec{N}$ $\mathrm{PaCO}_{2}$ at high tensions and underestimate $\mathrm{PaCO}_{2}$ at $\overrightarrow{\vec{F}}$ low tensions. ${ }^{11}$

Our inability to show any significant effect of age on $\mathrm{TcPO}_{2} / \mathrm{PaO}_{2}$ suggests that extrapolation of these $\stackrel{?}{\longrightarrow}$ relations from studies in neonates and in adults into the paediatric age range may be appropriate. The $\mathbb{D}$ effects of time on increasing $\mathrm{TcPo}_{2} / \mathrm{PaO}_{2}$ and de- $\stackrel{\Phi}{\overparen{D}}$ creasing $\mathrm{TcPCO}_{2} / \mathrm{PaCO}_{2}$ has several possible explana- 을 tions. Local heat may have changed the metabolism $\stackrel{\mathbb{D}}{-}$ of the underlying skin, shifted the local $\mathrm{O}_{2}$ dissociatiơ $\vec{\varphi}$ curve to the right, ${ }^{10}$ or a small air leak may have or developed under the electrodes.

In children requiring respiratory support who are not in shock $\mathrm{TcPO}_{2}$ and $\mathrm{TcPCO}_{2}$ bear constant and predictable relations to simultaneously measured arterial gas tensions, and are able to predict arterial $\stackrel{\circ}{\varnothing}$ values within clinically acceptable tolerances. Fur- $\cong$ ther work needs to be undertaken to define the limitations imposed by circulatory failure and $\exists$ whether similar accuracy can be obtained at lower electrode temperatures.

References

1 Cassidy G. Transcutaneous monitoring in the newborn infant. J Pediatr 1983;103:837-48.

2 Yip WC, Tay JS, Wong HB, Ho TF. Reliability of transcutaneous oxygen monitoring of critically ill children in a general pediatric intensive care unit. Clin Pediatr 1983;22: 윽 431-5.

${ }^{3}$ Monaco F, Nickerson BG, McQuitty JC. Continuous transcutaneous oxygen and carbon dioxide monitoring in the pediatric ICU. Crit Care Med 1982;10;765-6.

${ }^{4}$ Huch $\mathrm{R}$, Huch $\mathrm{A}$, Albani $\mathrm{M}$, et al. Transcutaneous $\mathrm{PO}_{2} \mathrm{O}$ monitoring in routine management of infants and children with $\mathrm{N}$ cardiorespiratory problems. Pediatrics 1976;57:681-90.

5 Yahav J, Mindorff $C$, Levison $H$. The validity of the trans- $\omega$ cutaneous tension method in children with cardiorespiratory problems. Am Rev Respir Dis 1981;124:586-7.

6 Tremper KK, Shoemaker WC, Shippy CR, Nolan LS. Transcutaneous $\mathrm{PCO}_{2}$ monitoring on adult patients in the ICU and $\$$ operating room. Crit Care Med 1981;9:752-5.

7 Lofgren $O$. Transcutaneous oxygen measurement in adult $T$ intensive care. Acta Anaesthesiol Scand 1979;23:534-4. 
${ }^{8}$ Severinghaus J, Stafford M, Bradley $\mathrm{A}$. TcPo ${ }_{2}$ electrode design, calibration and temperature gradient problems. Acta Anaesthesiol Scand 1978;68:(Suppl)118-22.

${ }^{9}$ Severinghaus J, Stafford M, Thurnstrom A. Estimation of skin metabolism and blood flow with $\mathrm{TcPo}_{2}$ and $\mathrm{TcPcO}_{2}$ electrodes by cuff occlusion of the circulation. Acta Anaesthesiol Scand 1978;68:(Suppl)99-105.

${ }^{10}$ Bradley A, Stupfel M, Severinghaus J. Effect of temperature on $\mathrm{PCO}_{2}$ and $\mathrm{PO}_{2}$ of blood in vitro. J Appl Physiol 1956;9:201-4
11 Tanner J. Fallacy of per weight and per surface area standards and their relation to spurious correlation. J Appl Physiol 1949;2:1-15.

Correspondence to Dr P Helms, Respiratory Unit, Hospital for Sick Children, Great Ormond Street, London WC1 3JH.

Received 17 June 1985

\section{One hundred years ago}

\section{Insurance and child mortality}

\section{The Lancet, 24 January 1885: 167}

A remarkable statement was lately made by Dr. Ritchie of Leek, respecting the rise in infant mortality since the practice of insuring the lives of children in their first year was introduced there. As at first reported, the mortality prior to this period was 15 per 1000 , and rose during it to 170 . Further evidence has shown that there is a clerical error in these figures, and that the excess in the death-rate consists in the difference between 156 and 186 per 1000 . This materially alters the aspect of the case. Still, the excess, though not absolutely so great, is decided, and, inasmuch as it is constant, calls for explanation. How much of it is due to so-called natural causes, such as prevalent disease, to accidents, to local changes affecting public health during the period of operation of the insurance system, and how much, if any, is to be laid directly at the door of the latter? Of course it is impossible for us or anyone to give a ready answer to this question. What is required is a prolonged investigation which will aim at ascertaining the various possible causes of illness and death which might be held accountable, and the various degrees of their action, during, before, and after the time in question. We must probably allow, however, that some such comparison has been drawn before a statement so pointed as Dr. Ritchie's has been publicly made. A medical officer of health is in the best position for knowing the results of all conditions ordinarily affecting health and illness in his district. The institution of a further inquiry is, however, very desirable for many reasons. Without wishing to blacken the reputation of human nature, we cannot but admit that there is ample evidence to show that infant life is less respected than it ought to be. It is a life which is only too easily taken, the means by which this may be criminally accomplished are many, their discovery at times is very difficult, and conviction for crimes of this nature is in many cases impossible. Neglect alone will take this life, errors of judgment in management can be turned into errors of purpose for its extinction. Thus, bread and biscuit have killed many children. They are among the "farm" foods of infancy. It would certainly be most unfair to conclude that the poor are naturally less affectionate towards their children than the wealthy. It is equally beyond question that unnatural parents are found, and not seldom in that class, as in all others. Moreover, poverty with its associations brings temptations and longings which well-conditioned people can hardly estimate. Then we must remember the many children born, one may say, without father or mother in the full sense-the illegitimate class. Charity, public or parental, is not always careful to preserve these amongst us. They become the charge of underpaid nurses, and are too often brought up anyhow. Their living is rather permitted than desired. With these facts before us, the placing of a premium of several pounds on the life of an infant is clearly a measure which, however desirable in suitable cases, requires at least a shrewd supervision in its working in order that it may not become an incentive to crime in the ill-disposed. 